\title{
PERCEPCION DE NIÑOS ESCOLARES FRENTE AL ABUSO SEXUAL
}

\author{
Ps. Roger Elizalde Bravo ${ }^{1}$ \\ Ps. Nebel Dávila Noriega \\ Dr. Mario Bulnes Bedón \\ Dr. César Sarria Joya
}

\begin{abstract}
RESUMEN
Se ha explorado el problema del abuso sexual en 391 escolares de ambos sexos, provenientes de centros educativos estatales de nivel primario, de estrato socioeconómico bajo y cuyas edades fluctúan entre los 07 a 14 años. Inicialmente se construyo un cuestionario de 32 ítems y una ficha sociodemográfica para determinar las características de la muestra.

Se encuentran diferencias significativas en función al sexo, los niños consideran edades de riesgo al abuso sexual entre 03 a 05 años, y las niñas las edades de 08 a 11 años.

Existen mayores temores y preocupaciones en las niñas de ser víctimas y ante cualquier acoso sexual prefieren comunicárselo a la madre antes que al padre. En general los menores presentan una alta valoración y estima hacia su cuerpo.
\end{abstract}

PALABRAS CLAVE: percepción, abuso sexual, violación sexual.

\section{ABSTRACT}

This study explorer the problem of the sexual abuse in 391 scholars of sex both, proceeding of centers state educative of primary level, of socioeconomic stratum short and of wich ages to fluctuate between the 7 or 14 ages. Initialy be constructed a questionary of 32 items and chip sociodemographic for to determinate the characteristics of the sample.

$B e$ to find different significative in function to sex the boys to considerate ages of rísk or abuse sex between 3 or 5 ages, and the girls the ages of 8 or 11 ages.

Existence greaters fears and preocupaty in the girls of to be victims and elk cualquier sex persecute preference communicative or the mother before who or the father. In general the childs to present or high assessment and to estimate toward your body.

KEY WORDS: perception, sexual abuse, sexual violation.

\footnotetext{
${ }^{1}$ Coordinador del Departamento Académico de la Facultad de Psicología de la UNMSM.
} 
Cada vez son más frecuentes y alarmantes los casos de abuso sexual en niños de uno u otro sexo y que son denunciados públicamente por los medios de comunicación en nuestro contexto social. Las modalidades de abuso son diversas, como manoseo o tocamientos, gestos groseros, asedio callejero, exhibicionismo, atentados contra el pudor, incesto, estupro, violación, etc.

Algunos reportes como el que refiere la revista Laides Home Journal (1983) enEE.UU., señala que el abuso sexual de niñas es cuatro veces más común que la violación de mujeres adultas. De cada cuatro niñas entre 05 a 13 años, una llega a ser victima de alguna forma de abuso sexual por parte de un adulto, sea a través de exhibicionismo, caricias impropias, violación o incesto.

B. Woolding (1985) en EE.UU., menciona que en dos años 1975 y 1978 el FBI reporta 56,090 y 67,131 casos de violación respectivamente; de éstos delitos, más del $50 \%$ no fueron denunciados y de ellos más del $60 \%$ ocurrió en niñas, encubriéndose éstos abusos.

J. Vilchez (1986) en Venezuela, en un estudio realizado en el Hospital de Maracaibo, encontró que el abuso sexual es cometido por familiares, amigos y vecinos en un $75 \%$ de casos; y por desconocidos en un $25 \%$.

$\mathrm{J}$.Anderson (1984) en una oficina médico legal, encuentra que de un total de 73 casos de menores maltratados, 64 niñas habían sido víctimas de abuso sexual; el agresor en el $31,5 \%$ de ellos fue alguien conocido por la menor, además los actos habían ocurrido en la propia casa de la víctima, siendo que el mayor número de ellas tenían entre 11 a 13 años, seguido por edades de 14 años; y el 16\% de las niñas tenían menos de 11 anos.

En nuestro país en el Ministerio de Justicia (1984) se encontró que de una muestra de 108 denuncias sobre maltrato en niños el 80\% fueron objeto de abuso sexual.

G. Tamayo y J.M. Gracia (1988) en un estudio realizado en el distrito de El Agustino, encontraron que un $60 \%$ de niñas que asistían a una parroquia para prepararse en la primera comunión, habían sido víctimas de agresiones sexuales en sus propios hogares.

Un artículo en la revista Cuanto (1991), informa que en los años 1980 a 1989 sobre denuncias de violaciones ocurridas en el país, la policía nacional registró 59,600 casos y la policía técnica 18,509 denuncias por el mismo delito. 
M. Rosas (1995) refiere que 5,000 niñas quedan embarazadas anualmente en el país; y en la Maternidad de Lima el 90\% de madres adolescentes de 12 a 16 años fueron víctimas de violación sexual.

El programa MAMIS del Instituto de Salud del Niño, atendió 118 casos de violencia contra menores, de ellos el $41,5 \%$ fueron atendidos por maltrato físico, $23 \%$ por abandono y negligencia, $22 \%$ por abuso sexual, $8,5 \%$ por intento de suicidio y $4,2 \%$ por maltrato emocional.

Las Defensorias Municipales de Niños y Adolescentes (DEMUNAS) de Lima, entre enero y febrero de 1995, detectaron 96 casos de abuso sexual el $75 \%$ eran niñas y $25 \%$ niños. De enero a junio de 1996 se registraron 135 casos el 79,3\% fueron niñas y el 20, $7 \%$ niños. Los casos detectados en Lima en los primeros seis meses de 1997 se incrementaron en $140 \%$ en comparación al año anterior y se observa que un 19,3\% de las víctimas fueron menores de 05 años; un 38,51\% entre 8 a 11 años y el 42,2\% de 12 a 18 años; las víctimas fueron mayormente mujeres en un 79,3\% en relación al $20 \%$ de varones.

El Ministerio Público tiene registrados entre los años 1996, 1997 y 1998 (enero a octubre) casos de violación de la libertad sexual por un total de 270, 345, y 146 respectivamente a cada año. De ellos existen violaciones a menores de 07 años: 29, 26 y 58 casos por año; menores de 07 años a menos de 10 años: 28, 13 y 11 respectivamente; edades de 10 a menos de 14 años: 85,75 y 48 años.

Está demostrado que las consecuencias producidas por el abuso sexual en la edad infantil generan grave daño emocional y psicológico en los niños, pudiendo ser a largo plazo devastador. El menor que es víctima de abuso sexual prolongado, usualmente desarrolla una perdida de autoestima, tiene la sensación de que no vale nada y adquiere una perspectiva anormal de la sexualidad. Puede volverse muy retraído, perder la confianza hacia todos los adultos, igualmente tiende a desarrollar variedad de pensamientos e ideas angustiantes, llegando inclusive a considerar el suicidio como un medio de escape al problema.

En su generalidad el niño no esta preparado ni tiene recursos para hacer frente al abuso sexual, más aún si conoce y aprecia a la persona que ha abusado de él, se siente atrapado entre la relación afectiva o la lealtad que siente hacia esa persona y el conocimiento moral de que las actividades sexuales son terriblemente malas. Luego, si el niño trata de romper con las relaciones sexuales, el abusador puede amenazarlo violentamente o retirarle su afecto. 
Lo cotidiano y que esta refrendado por los medios periodísticos, es que casi siempre el abuso sexual ocurre en el seno familiar, ya sea a manos del padre, padrastro, hermano $u$ otro pariente cercano. Otra posibilidad es que el abuso se realice fuera de la casa con un amigo, o la persona que lo cuida, un vecino, o un desconocido.

El presente estudio es de tipo exploratorio, efectuado sobre una muestra de 391 escolares de escuelas estatales primarias de los alrededores de Lima, de ambos sexos y de nivel socioeconómico bajo. Pretendemos conocer en los menores el nivel de conocimiento y manera de percibir éste tipo de problema, así como sus actitudes y probables conductas que manifestarían frente al abusador sexual.

\section{PLANTEAMIENTO DEL PROBLEMA E HIPOTESIS}

Consideramos que el abuso sexual en los niños, suele venir asociado al maltrato infantil físico, psicológico y al abandono negligente. Esta situación genera evidentemente serías consecuencias, como conductas desadaptativas y probables desordenes mentales, más aun cuando se generan situaciones de violencia. En la actualidad nuestros niños se encuentran desprotegidos y pueden ser abusados sexualmente con bastante facilidad en la calle, o a la salida del colegio, incluso en el mismo colegio o en su misma casa, pudiendo ser el autor o los autores otro niño de mayor edad o edad similar pero con experiencias desadaptativas, un familiar, una persona adulta conocida o desconocida. Es por ello que nuestra inquietud nos lleva a tratar de descubrir cuál es la concepción que los niños tienen respecto a éstos hechos, cómo siente el fenómeno del abuso sexual, cuáles la información que tiene al respecto y cuál es serían sus actitudes o conductas ante una posible agresión sexual. El planteamiento del problema se resume en las siguientes preguntas: ¿Cómo es que el niño percibe o siente el problema del abuso sexual?, y ¿Cuál es la información que tienen los niños frente al problema del abuso sexual?

La hipótesis de trabajo sustentada es:

H 1 Existen diferencias significativas en la percepción del fenómeno de abuso sexual infantil entre niños escolares de sexo masculino y femenino.

\section{OBJETIVOS}

Hacer un estudio de tipo exploratorio y descriptivo que nos permita conocer la opinión, así como el nivel de información que tienen los niños y niñas escolares pertenecientes a un estrato socioeconómico bajo, acerca del abuso sexual.

Conocer la incidencia, tipo de abuso, clases de agresor, vivencias subjetivas y efectos del abuso sexual infantil. 


\section{CONCEPTOS TEORICOS SOBRE EL ABUSO SEXUAL}

Sgroi, Canfíeld y Sarnacki (1986), consideran que el abuso sexual en niños (as) es un acto sexual impuesto a un niño (a) que carece de un desarrollo emocional maduro y consciente. La habilidad para atraer con engaños a un niño(a) hacia una relación sexual, se basa en la posición dominante y todo poderosa del adulto(a) o adolescente que comete el acto, en agudo contraste con la menor edad del niño(a), su dependencia y posición subordinada. La autoridad y el poder respaldan al abusador implícita o directamente, para coercionar al niño(a) a la sumisión sexual. Se suele incluir además en algunos casos amenazas y violencia física por parte del abusador. El abuso sexual abarca una serie de conductas que van desde gestos groseros, manoseo, asedio callejero, exhibicionismo, tocamientos, hasta la violación misma.

El médico holandés A. Koers (1979), señala los siguientes factores que se dan en el acto de abuso sexual:

1. El Abuso (explotación) sexual siempre constituye una forma de violencia fisica y/o mental por lo cual el adulto se aprovecha tanto de la confianza del niño como de su superioridad. El niño no puede comprender la gravedad del hecho a causa de su ignorancia, es decir no esta en condición de dar su consentimiento o de negarse libremente.

2. El abuso sexual no se limita necesariamente a la relación entre hombre y niña, aunque suele ser el caso más frecuente.

3. En la mayor parte de los casos el autor proviene del entorno social del menor y no es un extraño, en contra de lo que se suele creer.

4. El abuso sexual siempre tiene como consecuencia un retraso en su desarrollo. Los niños afectados sufren lesiones tanto fisicas como mentales, aunque las secuelas psíquicas se detectan más difícilmente y se manifiestan mucho tiempo después.

5. El abuso sexual generalmente no se produce de forma aislada, sino que muchas veces se prolonga durante años.

6. Es dificil establecer cuando las caricias cariñosas se convierten en un abuso sexual sin embargo los niños perciben de manera instintiva dónde empieza la explotación de su cuerpo. Aunque los contactos puedan resultar en un principio positivos para el niño, si el agresor tiene suficiente habilidad, el pequeño advertirá muy pronto en que momento cambia la situación y se convierte en desagradable.

7. El abuso sexual se produce cuando el adulto se sirve de su autoridad para aprovecharse de la relación de dependencia del niño. Esta situación de poder no solo se establece entre adulto y niño, sino también entre hombre y mujer. El abuso busca ante todo satisfacer de forma consciente o inconsciente las necesidades del 
adulto.

H. Saller (1987), clasifica el abuso sexual en tres categorías principales:

1. Manifestaciones claras e inequívocas.

- relaciones sexuales genitales orales (cunilingüismo, felación).

- penetración en el ano del niño con el dedo(s), pene u objetos extraños.

- penetración en la vagina de la niña con dedo(s), pene u objetos extraños.

2. Abusos considerados de "menor gravedad" por algunos adultos, haciendo uso del cuerpo infantil su propia satisfacción:

- tocamiento o manipulación de los genitales del niño.

- obligar al niño a tocar los genitales del adulto o manipularlos, a menudo bajo la apariencia de "juego".

- masturbación en presencia del niño.

- obligar al niño a masturbarse en presencia del adulto.

- frotamiento del pene contra el cuerpo del niño.

- mostrar ilustraciones pornográficas al niño.

- hacer fotografías pornográficas o peliculas del/con el niño.

3. Comportamiento de abuso sexual incipientes:

- el adulto se muestra desnudo delante del niño.

- el adulto le muestra sus genitales al niño.

- el adulto quiere dar el "visto bueno" al cuerpo del niño.

- el adulto observa al niño al desvestirse, bañarse, lavarse, en el aseo; en algunos acosos puede ofrecerle su ayuda para ello.

- el adulto besa al niño de forma muy intima ("beso con lengua").

- iniciar prematuramente al niño en la sexualidad para satisfacer las necesidades exhibicionistas y/o de mirón del adulto.

Otro autor, Garbarino (1986) hace una clasificación del maltrato infantil mencionando entre ellos al maltrato físico, abandono físico, maltrato emocional, abandono emocional, maltrato prenatal, etc. y entre ellos menciona el abuso sexual, que lo define como cualquier clase de contacto sexual con un niño menor de 18 años por parte de un familiar o tutor adulto desde una posición de poder o autoridad sobre el niño. Seguidamente señala las siguientes categorías:

Categoría A, INCESTO, contacto físico sexual o intercurso sexual por un pariente de consanguinidad lineal (padre/madre, abuelo(a), tío(a), sobríno(a) o con figuras adultas que esten cubriendo de manera estable el papel de figuras paternales (padres adoptivos o parejas estables)

Categoría B, VIOLACION, contacto fisico sexual o intercurso sexual por una persona 
adulta exceptuando los casos señalados en el apartado anterior (incesto)

Categoría $\boldsymbol{C}$, VEJACION SEXUAL, conducta sexual con un menor cuando tal contacto es usado para la estimulación o gratificación de las necesidades o deseos sexuales de una persona. Incluye tocamiento o manoseo del adulto, o alentar, forzar o permitir al niño que toque de manera inapropiada partes intimas (genitales, pechos, muslos y nalgas o las ropas que cubren estas partes).

Categoría D, ABUSO SEXUAL SIN CONTACTO, solicitud indecente o seducción verbal explícita al menor. Exponer los órganos sexuales al niño, con el propósito de obtener excitación o gratificación sexual, agresión o degradación. Realizar el acto sexual intencionadamente en la presencia de un menor con el objeto de buscar excitación o gratificación sexual, agresión, degradación u otros propósitos semejantes.

Se puede concluir que abuso sexual es toda agresión física o síquica en contra del área sexual del niño, que se ejerce en contra de su voluntad y así mismo afecta su bienestar, viola sus derechos y atenta contra su salud mental.

Es importante señalar que las consecuencias que originan las agresiones sexuales a los niños(as), son de consideración, y podemos diferenciarlas en lesiones fisicas y psicológicas:

a. Lesiones físicas, son las más comunes aunque no necesariamente el abuso sexual puede condicionar una lesión física, entre ellas podemos considerar las siguientes: lesiones en los genitales, mordeduras, hematomas, estrías a causa de los golpes sobre la región pectoral y genital y sobre otras zonas erógenas (muslos, vientre, cuello, nalgas, etc.), enfermedades venéreas que se trasmiten por contacto sexual (gonorrea en región laringea y genital), hemorragia o flujo en la región genital, frecuente prurito, excoriaciones, enrojecimiento cutáneo, embarazos tempranos.

b. Lesiones psicológicas: sentimientos de vergüenza y culpa, perdida general de: confianza, sensación de impotencia, miedos concretos o indeterminados, aíslamiento, dudas respecto a lo se percibe, mutismo, falta de autoestima, desdoblamiento de la personalidad a causa de una inseguridad total. Se agregan también estados de turbación general, depresiones que pueden llegar hasta el suicidio (o intento de suicidio), trastornos del sueño, trastornos del habla, dificultades de concentración, disminución del rendimiento escolar, ausencia de contacto con la gente o problemas para relacionarse, aparición o reaparición de síntomas neuróticos, como enuresis, incapacidad para retener heces, tartamudeo, manías, huidas, dispersión, agresiones (contra otros y/o autolesiones como morderse las uñas o arrancarse el pelo, comportamiento sexualizado "prematuro" o bien retroceso a etapas de desarrollo anteriores, comportamiento autoerótico extremo (por ejemplo masturbaciones frecuentes, también frente a los demás), trastornos alimenticios (anorexia, bulimia), dolores sin causa física aparentes, otros trastornos psicosomáticos como asma, 
enfermedades cutáneas, alergias, molestias epigástricas, refugio en dependencias (drogas), "manifestaciones de desamparo" (ej, problemas educativos, comportamiento criminal, promiscuidad sexual, prostitución), así como el abandono de la propia persona con desinterés total por la higiene, la ropa, el aspecto personal, miedo, repulsa hacia la sexualidad, trastornos sexuales (pérdida de la libido, estados de fijación sobre determinados tipos de pareja o prácticas sexuales (necesidad de repetir los mismos esquemas de comportamiento), neurosis graves (fobias, manías como la de lavarse constantemente), cambios en la personalidad y psicosis.

\section{METODOLOGIA}

En éste estudio se recoge la información que la población infantil tiene frente al problema del abusos sexual en nuestro medio, y verificar si existen diferencias significativas entre niños vs. niñas.

\section{MUESTRA}

La muestra ha sido recogida mediante el procedimiento del método probabilístico al azar, siendo la unidad de análisis un niño escolar. El número de población muestral corresponde a un total de 391 niños, pertenecientes al estrato socioeconómico bajo, de los cuales 184 son varones $(47,1 \%)$ y 207 mujeres $(52,9 \%)$, los mismos que proceden de colegios estatales de los alrededores de Lima:

C.E. 1260 de Ate Vitarte; 3059 de Comas; 071 de San Juan de Lurigancho; 6029 de Villa María del Triunfo; 6063 de Villa el Salvador; Ramiro Prialé del Callao; y 5035 del distrito de Reynoso, ver Tabla $N^{\circ} 01$.

Tabla $\mathbf{N}^{\circ} 1$

Colegios y Numero de Sujetos

\begin{tabular}{|ll|c|c|c|c|c|c|}
\hline $\begin{array}{l}\text { CE. } \\
\text { Prim, }\end{array}$ & Distrito & $\mathbf{H}$ & $\%$ & $\mathbf{M}$ & $\%$ & $\mathrm{~T}$ & $\%$ \\
\hline 1260 & Ate & 30 & 7.7 & 34 & 8.7 & 64 & 16.4 \\
3059 & Comas & 21 & 5.4 & 24 & 6.1 & 45 & 11.5 \\
71 & SJ.L. & 28 & 7.2 & 36 & 9.2 & 64 & 16.4 \\
6029 & V.M.T. & 21 & 5.4 & 22 & 5.6 & 43 & 11.0 \\
6063 & V.E.S. & 32 & 8.1 & 34 & 8.7 & 66 & 16.8 \\
R.Priale & Callao & 30 & 7.7 & 37 & 9.5 & 67 & 17.2 \\
5035 & Reynoso & 22 & 5.6 & 20 & 5.1 & 42 & 10.7 \\
\hline TOTAL & & 184 & 47.1 & 20 & 52.9 & 391 & 100 \\
\hline
\end{tabular}

Las edades están comprendidas entre los 07 y 14 años, cuyas edades más sobresalientes corresponden a 09, 10 y 11 años, ver $\boldsymbol{T a b l a} \boldsymbol{N}^{\circ} \boldsymbol{0 2}$.

Tabla $\mathbf{N}^{\circ} 2$ 


Edades de la Muestra
\begin{tabular}{|r|c|c|}
\hline dades & No. de Ss & $\%$ \\
\hline 14 & 2 & 0.51 \\
13 & 18 & 4.60 \\
12 & 31 & 7.93 \\
11 & 56 & 14.30 \\
10 & 118 & 30.18 \\
9 & 127 & 32.48 \\
8 & 33 & 8.44 \\
7 & 6 & 1.53 \\
\hline TOTAL & 391 & 100.0 \\
\hline
\end{tabular}

Los niveles de escolaridad varían entre el $2^{\circ}$ y $6^{\circ}$ grado de primaria, siendo los niveles más notorios porcentualmente el $5^{\circ}$ y $4^{\circ}$ Grado de Primaria, lo que se puede apreciar en la Tabla $N^{\circ} 03$.

Tabla $\mathbf{N}^{\circ} 3$

\section{Grados de Escolaridad de la Muestra}

\begin{tabular}{|c|c|c|}
\hline Grados & No. de Ss. & $\%$ \\
\hline 6to & 44 & 6.25 \\
5to & 59 & 10.94 \\
4to & 245 & 53.12 \\
3ro & 34 & 25.00 \\
2do & 9 & 4.69 \\
\hline TOTAL & 391 & 100.0 \\
\hline
\end{tabular}

\section{INSTRUMENTO}

El presente cuestionario se construyo sobre la base de 45 Ítems, luego fue sometido a una prueba de aplicación piloto en niños de ambos sexos de un centro educativo primario. Luego del proceso de depuración quedo conformado por 32 Ítems.

Para determinar el lugar, sexo, edad, escolaridad, composición familiar y vivienda se ha incluido inicialmente al cuestionario una encuesta sociodemográfica

Las instrucciones para su administración son las siguientes: "A continuación de cada pregunta deberás marcar con un aspa $(\mathrm{X})$ en el cuadrado, según consideres que la respuesta que eliges esta de acuerdo a tu manera de pensar".

Las áreas que explora éste cuestionario corresponden a las siguientes:

1. Influencia de los medios de comunicación, Ítems: 1,7, 12-B.

2. Actitud frente al niño abusado sexualmente, Ítems: 10, 16, 3, 8, 2, 4, 17, 20, 14, 15, 27, 12-A, 12-B. 
3. Temor a ser abusado sexualmente, Ítems: 30, 23 ,21, 24, 26, 22.

4. Conducta frente al agresor sexual, Ítems: 6, 32, 9, 28, 5.

5. Criterio valorativo respecto a su cuerpo, ítems: 25, 18, 19, 31, 29.

6. Ambito de procedencia del abusador sexual, ítems: 11, 13.

Los típos de ítems construidos son 18 de tipo cerrado para responder $\mathrm{Si}$ o No; 02 complementarios de tipo abierto; 01 complementario de alternativas y 14 items de alternativas diversas

\section{RESULTADOS}

Los resultados encontrados se han procesado porcentualmente con relación a las respuestas emitidas por los sujetos de la muestra en cada item. Así mismo mediante el estadístico del Ji-cuadrado se determino comparativamente las diferencias de las respuestas de los niños vs. las niñas.

A continuación se presentan los hallazgos encontrados en la población infantil diferenciándose por áreas:

INFLUENCIA DE LOS MEDIOS DE COMUNICACIÓN, (ver Tabla No.04) encontramos que el $67.0 \%$ (ítem 01) de la muestra considera que las fotografías de desnudos que aparecen en los quioscos de periódicos enseñan o incentivan a las personas a cometer actos de abuso sexual con los niños.

Igualmente el $65.7 \%$ (i .07) opina que las personas que ven películas de violencia sexual en el cine o la TV. presentaría tendencias a cometer actos de abuso sexual en perjuicio de los niños

Así mismo se puede observar que los niños obtienen información sobre éste tipo de abusos a través de la TV. en un 41.9\% (ítem 12-B.5) y de los periódicos en un $25.0 \%$ (i. 12-B.4).

Tabla $\mathbf{N}^{\circ} 4$

"Influencia de los Medios de Comunicación

\begin{tabular}{|c|c|c|c|c|c|c|c|c|}
\hline \multirow{3}{*}{ ltem } & \multirow{3}{*}{ Contenido de los Items } & \multicolumn{6}{|c|}{ Respuestas Afirmativas } & \multirow{3}{*}{$\mathbf{X} 2$} \\
\hline & & \multicolumn{2}{|c|}{ Hombres } & \multicolumn{2}{|c|}{ Mujeres } & \multicolumn{2}{|c|}{ Total } & \\
\hline & & $\mathbf{f}$ & $\%$ & $\mathbf{f}$ & $\%$ & $\mathbf{f}$ & $\%$ & \\
\hline 1 & $\begin{array}{l}\text { ¿Las fotografias de desnudos en } \\
\text { los diarios enseñan a la gente a } \\
\text { ser abusivos sexualmente con los } \\
\text { niños? }\end{array}$ & 127 & 32.5 & 135 & 34.5 & 262 & 67.0 & 0.43659 \\
\hline 7 & $\begin{array}{l}\text { La persona que ve películas de } \\
\text { violencia sexual en el cine o Tv. } \\
\text { ¿Podría abusar sexualmente de } \\
\text { los niños? }\end{array}$ & 119 & 30.4 & 138 & 35.3 & 257 & 65.7 & 0.71646 \\
\hline $\begin{array}{l}\text { 12- } \\
\text { B }\end{array}$ & $\begin{array}{l}\text { ¿¿Dónde fue? } \\
\text { 12-B.1. En tu colegio } \\
\text { 12-B.2. En tu casa } \\
\text { 12-B.3. En el barrio } \\
\text { 12-B.4. En los periódicos } \\
\text { 12-B.5. En la TV. }\end{array}$ & $\begin{array}{l}12 \\
11 \\
21 \\
30 \\
52\end{array}$ & $\begin{array}{l}4.6 \\
4.2 \\
8.1 \\
11.5 \\
20.0\end{array}$ & $\begin{array}{r}9 \\
7 \\
26 \\
35 \\
57\end{array}$ & $\begin{array}{l}3.5 \\
2.7 \\
10.0 \\
13.5 \\
21.9\end{array}$ & $\begin{array}{r}21 \\
18 \\
47 \\
65 \\
109\end{array}$ & $\begin{array}{l}8.1 \\
6.9 \\
18.1 \\
25.0 \\
41.9\end{array}$ & $\begin{array}{r}0.61740 \\
021292 \\
0.75590 \\
0.90866 \\
0.54738\end{array}$ \\
\hline
\end{tabular}


ACTITUD FRENTE AL NIÑO ABUSADO SEXUALMENTE, (ver Tabla No.05) en ésta área, el $27.7 \%$ (i. 10.5) de la muestra considera que hay abuso sexual cuando alguna persona hace tocamiento de sus partes sexuales; el $19.1 \%$ si alguien le manosea su cuerpo; el $17.9 \%$ cuando una persona extraña le pide al niño que se quite su ropa interior; el $10.2 \%$ si otra persona le pide que haga tocamiento de sus partes sexuales; el $9.4 \%$ cuando alguna persona se desnuda en presencia del niño.

Respecto a aquellos niños que fueron víctimas de abuso sexual, el $50.4 \%$ ( i.16.1) opina que ello se debe a que fueron engañados supuestamente por el violador; el 18.8\% (i.16.5) porque nunca recibieron una orientación al respecto; el 16.9\% (i.16.2) porque recibieron dulces o caramelos del violador; el $10.1 \%$ (i.16.4) porque no le contaron a sus padres o probablemente no se comunico este hecho a sus padres. Solo el $3.9 \%$ (i.16.3) responde que el mismo niño abusado sexualmente tuvo la culpa

En cuanto a la edad de mayor peligro en el que puede ser abusado sexualmente un niño, encontramos que el 67.6\% (i.17.1) responde que es entre los 03 a 05 años de edad, de los cuales el $20.20 \%$ son niños y el $17.4 \%$ niñas, siendo estas diferencias significativas al 0.05. Seguidamente en proporciones menores: $43.7 \%$ (i.17.3) refiere que la edad de peligro esta entre los 08 y 10 años de edad, existiendo diferencias porcentuales entre ambos sexos por lo que es más alta la opinión afirmativa de las niñas $26.0 \%$ respecto a los niños $17.7 \%$, con un nivel de significación del 0.05 .

En lo concerniente a la manera de ser percibido al menor víctima de abuso sexual, la muestra, en un $63.7 \%$ (i. 03.4) lo percibe como psicológicamente traumado; el $21.4 \%$ (i. 03.2) enfermo; el 9.3\% (i.03.3) sexual mente anormal

Ante la expresión o apariencia física de niños violados sexualmente, el 56.4\% (í 08.1) de la muestra los percibe como sujetos tristes, de ellos observan esto las niñas en un $34.2 \%$ comparativamente a los niños $22.2 \%$, encontrándose diferencias significativas al 0.05; el 20.3\% (i. 08.3) los percibe como afeminados o los conceptúa dentro del argot popular como "maricones", en éste Ítem los niños responden afirmativamente el $13.1 \%$ en tanto que las mujeres el 7.2\%, encontrándose diferencias significativas al $0.05 ; \mathrm{y}$ finalmente como malos estudiantes o que su rendimiento escolar es bajo en la escuela, el $14.9 \%$ (i.08.5).

Sobre el ¿qué hacer? con un niño que fue abusado sexual mente, encontramos que el 49,4\% (1.02.3) señala que se le debe ofrecer protección; el 45.4\% (i.02.2) opinan que se le debe llevar a la policia. Seguidamente respecte a la atención que se le debe brindar a la víctima, el 49.0\% (i.04.2) de la muestra considera que debe recibir atención psicológica; y el 37.9\% (i.04.1) atención médica.

Respecto al niño que ha sido víctima de abuso sexual, el 36,3\% (i.14.6) manifiesta que se debería recurrir inmediatamente a la policía para denunciar el hecho, aquí los varones 
están de acuerdo en un $19.0 \%$ comparativamente a las mujeres (17.3\%), encontrándose diferencias significativas al 0.05 ; e $128.7 \%$ (i.14.2) responde que se debe poner en conocimiento del hecho a su mamá, probablemente antes que a su padre, siendo más alta la proporción de niñas que responden afirmativamente $(20.3 \%)$ comparativamente a los niños (8.4\%), existiendo diferencias significativas al 0.05 ; y finalmente hay un grupo, el 20.9\% (i.14.1) quienes consideran que se le debe decir inmediatamente a su papá.

Sobre los menores que corren mayor peligro de ser abusados sexualmente, el $65.3 \%$ (i.15.2) opina que son las niñas quienes estarían mayormente expuestas, encontrándose proporciones ligeramente altas en las respuestas de las niñas (37.6\%) comparativamente a los niños $(27.7 \%)$, y por el Ji-cuadrado encontramos diferencias significativas del 0.05. Luego, un 23.9\% (i.15.3) responde que son las mujeres jóvenes quienes correrían el peligro de ser abusadas sexualmente; y finalmente el $0.8 \%$ (i.15.1) de la muestra considera que son los niños.

El conocimiento o información que la muestra tiene respecto a niños que han sido violados sexualmente es del $58.1 \%$ (i.12-A); por el contrario el $41.9 \%$ desconoce sobre

Tabla $\mathbf{N}^{\circ} 5$

Actitud frente al niño abusado sexualmente

\begin{tabular}{|c|c|c|c|c|c|c|c|c|}
\hline \multirow{3}{*}{ Item } & \multirow{3}{*}{ Contenido de los Items } & \multicolumn{7}{|c|}{ Respuestas Afirmativas } \\
\hline & & \multicolumn{2}{|c|}{ Hombres } & \multicolumn{2}{|c|}{ Mujeres } & \multicolumn{2}{|c|}{ Total } & \multirow{2}{*}{$\mathrm{X} 2$} \\
\hline & & $\mathbf{f}$ & $\%$ & $\mathbf{f}$ & $\%$ & f & $\%$ & \\
\hline \multirow{9}{*}{10} & $\begin{array}{l}\text { ¿Cuándo consideras, que hay abuso } \\
\text { sexual en un niño? }\end{array}$ & & & & & & & \\
\hline & 10.1. Si alguien lo quiere tocar & 8 & 1.6 & 18 & 3.6 & 26 & 5.2 & 0.13757 \\
\hline & 10.2. Si alguien lo quiere besar & 6 & 1.2 & 14 & 2.8 & 20 & 4.0 & 0.12209 \\
\hline & 10.3. Si alguien lo quiere manosear & 41 & 8.2 & 55 & 10.9 & 96 & 19.1 & 0.35462 \\
\hline & 10.4. Si lo obligan a ver pornografía & 17 & 3.4 & 16 & 3.2 & 33 & 6.6 & 0.57076 \\
\hline & 10.5. Si le tocan sus partes sexuales & 62 & 12.4 & 77 & 15.3 & 139 & 27.7 & 0.51755 \\
\hline & 10.6. Si un extraño le pide quitarse la ropa & 38 & 7.6 & 52 & 10.4 & 90 & 18.0 & 0.32089 \\
\hline & 10.7. Si alguien le pide que le toque & 21 & 4.2 & 30 & 6.0 & 51 & 10.2 & 0.38782 \\
\hline & 10.8. Si alguien se desnuda en su presencia & 24 & 4.8 & 23 & 4.6 & 47 & 9.4 & 0.53255 \\
\hline
\end{tabular}




\begin{tabular}{|c|c|c|c|c|c|c|c|c|}
\hline \multirow{3}{*}{ Item } & \multirow{3}{*}{ Contenido de los Items } & \multicolumn{6}{|c|}{ Respuestas afirmativas } & \multirow{3}{*}{$\mathrm{X} 2$} \\
\hline & & \multicolumn{2}{|c|}{ hombres } & \multicolumn{2}{|c|}{ Mujeres } & \multicolumn{2}{|c|}{ Total } & \\
\hline & & f & $\%$ & f & $\%$ & f & $\%$ & \\
\hline 16 & $\begin{array}{l}\text { Los niños víctimas de abuso sexual fue } \\
\text { porque } \\
\text { 16.1. Fueron engañados } \\
\text { 16.2. Recibieron a cambio dulces } \\
\text { 16.3. Ellos tuvieron la culpa } \\
\text { 16.4. No les contaron nada a su padres } \\
\text { 16.5. Nunca fueron orientados }\end{array}$ & $\begin{array}{l}94 \\
29 \\
10 \\
19 \\
40\end{array}$ & $\begin{array}{r}22.7 \\
7.0 \\
2.4 \\
4.6 \\
9.6\end{array}$ & $\begin{array}{c}115 \\
41 \\
6 \\
23 \\
38\end{array}$ & $\begin{array}{l}27.7 \\
9.9 \\
1.5 \\
5.5 \\
9.2\end{array}$ & $\begin{array}{l}209 \\
70 \\
16 \\
42 \\
78\end{array}$ & $\begin{array}{c}50.4 \\
46.9 \\
3.9 \\
10.1 \\
18.8\end{array}$ & $\begin{array}{l}0.43783 \\
0.31994 \\
0.19883 \\
0.82966 \\
0.37559\end{array}$ \\
\hline 3 & $\begin{array}{l}\text { ¿Cómo consideras a los niños que han } \\
\text { sido víctimas de abuso sexual? } \\
\text { 3.1. Normales } \\
\text { 3.2.Enfermos } \\
\text { 3.3. Sexualmente anormal } \\
\text { 3.4. Psicológicamente traumados }\end{array}$ & $\begin{array}{c}8 \\
42 \\
19 \\
114\end{array}$ & $\begin{array}{c}2.0 \\
10.6 \\
4.8 \\
28.7\end{array}$ & $\begin{array}{c}14 \\
43 \\
18 \\
139\end{array}$ & $\begin{array}{c}3.5 \\
10.8 \\
4.5 \\
35\end{array}$ & $\begin{array}{c}22 \\
85 \\
37 \\
253\end{array}$ & $\begin{array}{c}5.5 \\
21.4 \\
9.3 \\
63.7\end{array}$ & $\begin{array}{l}0.38171 \\
0.58585 \\
0.56009 \\
0.34945\end{array}$ \\
\hline 8 & $\begin{array}{l}\text { Los niños violados o abusados } \\
\text { sexualmente suelen ser: } \\
\text { 8.1. Tristes }(*) \\
\text { 8.2. Alegres } \\
\text { 8.3. Afeminados ("maricón") }\left(^{*}\right) \\
\text { 8.4. Pleitistas } \\
\text { 8.5. No rinden en la escuela } \\
\end{array}$ & $\begin{array}{c}90 \\
8 \\
53 \\
8 \\
29\end{array}$ & $\begin{array}{c}22.2 \\
2.0 \\
13.1 \\
2.0 \\
7.2 \\
\end{array}$ & $\begin{array}{c}138 \\
12 \\
29 \\
6 \\
31 \\
\end{array}$ & $\begin{array}{l}34.2 \\
3.0 \\
7.2 \\
1.5 \\
7.7 \\
\end{array}$ & $\begin{array}{c}228 \\
20 \\
82 \\
14 \\
60 \\
\end{array}$ & $\begin{array}{c}56.4 \\
5.0 \\
20.3 \\
3.5 \\
14.9 \\
\end{array}$ & $\begin{array}{l}0.00059 \\
0.52522 \\
0.00027 \\
0.42976 \\
0.25940 \\
\end{array}$ \\
\hline 2 & $\begin{array}{l}\text { ¿Qué hacer con un niño abusado } \\
\text { sexualmente? } \\
\text { 2.1. Nada } \\
\text { 2.2 .Llevarlo a la policía } \\
\text { 2.3. Protegerlo } \\
\text { 2.4. Rechazarlo }\end{array}$ & $\begin{array}{c}11 \\
83 \\
88 \\
2\end{array}$ & $\begin{array}{c}2.7 \\
20.6 \\
21.8 \\
0.5\end{array}$ & $\begin{array}{c}5 \\
100 \\
111 \\
3\end{array}$ & $\begin{array}{c}1.3 \\
24.8 \\
27.6 \\
0.7\end{array}$ & $\begin{array}{c}16 \\
183 \\
199 \\
5\end{array}$ & $\begin{array}{c}4.0 \\
45.4 \\
49.4 \\
1.2\end{array}$ & $\begin{array}{l}0.72420 \\
0.25038 \\
0.29756 \\
0.75897\end{array}$ \\
\hline 4 & $\begin{array}{l}\text { Un niño violado debe ser atendido por } \\
\text { 4.1. El médico } \\
\text { 4.2. El psicólogo } \\
\text { 4.3. El profesor } \\
\text { 2.3. El sacerdote } \\
\text { 2.4. Por nadie }\end{array}$ & $\begin{array}{c}70 \\
87 \\
5 \\
14 \\
7\end{array}$ & $\begin{array}{r}17.3 \\
21.5 \\
1.3 \\
3.5 \\
1.7\end{array}$ & $\begin{array}{c}83 \\
111 \\
3 \\
17 \\
7\end{array}$ & $\begin{array}{c}20.6 \\
27.5 \\
0.7 \\
4.2 \\
1.7\end{array}$ & $\begin{array}{c}153 \\
198 \\
8 \\
31 \\
14\end{array}$ & $\begin{array}{l}37.9 \\
49 \\
2.0 \\
7.7 \\
3.4\end{array}$ & $\begin{array}{l}0.73832 \\
0.25038 \\
0.36864 \\
0.84859 \\
0.80712\end{array}$ \\
\hline 17 & $\begin{array}{l}\text { Edad en que un niño podría ser } \\
\text { abusado sexualmente } \\
\text { 17.1. De } 3 \text { a } 5 \text { años }(*) \\
\text { 17.2. De } 6 \text { a } 7 \text { años } \\
\text { 17.3. De a } 8 \text { a } 10 \text { años }(*)\end{array}$ & $\begin{array}{l}79 \\
34 \\
72\end{array}$ & $\begin{array}{c}20.2 \\
8.4 \\
17.7\end{array}$ & $\begin{array}{c}67 \\
49 \\
106\end{array}$ & $\begin{array}{c}17.4 \\
12 \\
26\end{array}$ & $\begin{array}{c}146 \\
83 \\
178\end{array}$ & $\begin{array}{l}37.6 \\
20.4 \\
43.7\end{array}$ & $\begin{array}{l}0.02541 \\
0.22966 \\
0.02135\end{array}$ \\
\hline
\end{tabular}




\begin{tabular}{|c|c|c|c|c|c|c|c|c|}
\hline \multirow{3}{*}{ Item } & \multirow{3}{*}{ Contenido de los Items } & \multicolumn{6}{|c|}{ Respuestas afirmativas } & \multirow{3}{*}{$\mathbf{X} 2$} \\
\hline & & \multicolumn{2}{|c|}{ hombres } & \multicolumn{2}{|c|}{ Mujeres } & \multicolumn{2}{|c|}{ Total } & \\
\hline & & $\mathbf{f}$ & $\%$ & $\mathbf{f}$ & $\%$ & f & $\%$ & \\
\hline 20 & $\begin{array}{l}\text { Cuando te ofrecen dinero o un } \\
\text { regalo a cambio de mantener en } \\
\text { secreto un acto desagradable. ¿Tú } \\
\text { lo aceptas? }\end{array}$ & 4 & 1.0 & 4 & 1.0 & 8 & 2.0 & 0.47520 \\
\hline 14 & $\begin{array}{l}\text { ¿Qué debería hacer un niño } \\
\text { abusado sexualmente? } \\
\text { 14.1. Contárselo a su papá } \\
\text { 14.2. Contárselo a su mamá } \\
\text { 14.3. Decirle a su profesor } \\
\text { 14.4. Decirle a su amigo(a) } \\
\text { 14.5. Decirle a su hermano(a) } \\
\text { 14.6. Decirle a la policía }(*) \\
\text { 14.7. Decirle a cualquier familiar } \\
\text { 14.8. Quedarse callado }\end{array}$ & $\begin{array}{c}41 \\
40 \\
14 \\
1 \\
4 \\
90 \\
13 \\
2 \\
\end{array}$ & $\begin{array}{l}8.7 \\
8.4 \\
3.0 \\
0.2 \\
0.8 \\
19 \\
2.7 \\
0.4 \\
\end{array}$ & $\begin{array}{c}58 \\
96 \\
9 \\
1 \\
7 \\
82 \\
14 \\
2 \\
\end{array}$ & $\begin{array}{c}12.2 \\
20.3 \\
1.9 \\
0.2 \\
1.5 \\
17.3 \\
3.0 \\
0.4 \\
\end{array}$ & $\begin{array}{c}99 \\
136 \\
23 \\
2 \\
11 \\
172 \\
27 \\
4 \\
\end{array}$ & $\begin{array}{c}20.9 \\
28.7 \\
4.9 \\
0.4 \\
2.3 \\
36.3 \\
5.7 \\
0.8 \\
\end{array}$ & $\begin{array}{l}0.28660 \\
0.00000 \\
0.16344 \\
0.92762 \\
0.48152 \\
0.05244 \\
0.88457 \\
0.89752 \\
\end{array}$ \\
\hline 15 & $\begin{array}{l}\text { ¿Quiém corre peligro de ser } \\
\text { abusado sexualmente? } \\
\text { 15.1. Los niños } \\
\text { 15.2. Las niñas }(*) \\
\text { 15.3. Las mujeres jóvenes }\end{array}$ & $\begin{array}{c}27 \\
115 \\
50 \\
\end{array}$ & $\begin{array}{c}7.0 \\
27.7 \\
12.1 \\
\end{array}$ & $\begin{array}{c}8 \\
156 \\
49 \\
\end{array}$ & $\begin{array}{c}3.8 \\
37.6 \\
11.8 \\
\end{array}$ & $\begin{array}{c}45 \\
271 \\
99 \\
\end{array}$ & $\begin{array}{l}10.8 \\
65.3 \\
23.9 \\
\end{array}$ & $\begin{array}{l}0.05929 \\
0.00929 \\
0.39298 \\
\end{array}$ \\
\hline 12-A & $\begin{array}{l}\text { ¿Conoces niños que han sido } \\
\text { violados sexualmente? }\end{array}$ & 109 & 27.87 & 118 & 30.17 & 227 & 58.04 & 0.83534 \\
\hline 12-B & $\begin{array}{l}\text { ¿dónde fue? } \\
\text { 12-B.1 En tu colegio } \\
\text { 12-B.2 En tu casa } \\
\text { 12-B.3 En el barrio } \\
\text { 12-B.4 En los periódicos } \\
\text { 12-B.5 En la TV }\end{array}$ & $\begin{array}{l}12 \\
11 \\
21 \\
30 \\
52\end{array}$ & $\begin{array}{c}4.6 \\
4.2 \\
8.1 \\
11.5 \\
20\end{array}$ & $\begin{array}{c}9 \\
7 \\
26 \\
35 \\
57\end{array}$ & $\begin{array}{c}3.5 \\
2.7 \\
10.0 \\
13.5 \\
21.9\end{array}$ & $\begin{array}{c}21 \\
18 \\
47 \\
65 \\
109\end{array}$ & $\begin{array}{c}8.1 \\
6.9 \\
18.1 \\
25 \\
41.9\end{array}$ & $\begin{array}{l}0.61740 \\
0.21292 \\
0.75590 \\
0.90866 \\
0.54738\end{array}$ \\
\hline
\end{tabular}

(*) Significativo al 0.05

la existencia de niños violados. Sin embargo parece ser que la única fuente de información para los niños es la TV. en un 41.9\% (i.12-B.5); los periódicos el 25.0\%; y los comentarios o conversaciones en el barrio o localidad en un $18.1 \%$.

TEMOR A SER ABUSADO SEXUALMENTE (ver Tabla No. O6) en el supuesto que alguien haya querido abusar sexualmente de los niños (as) de la muestra, ésta probable intención se ha dado en el 19.7\% (i.30); en tanto que el $80.3 \%$ de la población no registra este tipo de experiencia. 
El $80.3 \%$ (i.23) de los niños manifiestan sus preocupaciones y temores, al tener conocimiento de la existencia de un menor que haya sido violado, de ellos las mujeres presentan porcentajes más altos en un $45.5 \%$ comparativamente a los varones $(34.8 \%)$, encontrándose entre ambos grupos que existen diferencias significativas del 0.05 .

El 97.7\% (i.21) manifiesta que no aceptaría algún regalo o dinero de una persona, a cambio de mantener en secreto un acto desagradable. Igualmente el 94.6\% (i.24) rechazaría a la persona que le ofrecería llevarlo a pasear, sin el consentimiento de sus padres.

En cuanto a la pregunta que plantea "si hubieras sido abusado sexualmente ¿esto para ti sería?", la muestra responde en un $58.0 \%$ (i.26) que sería una situación dolorosa, siendo más alto porcentualmente la opinión de las niñas $34.4 \%$ comparativamente a los niños (23.6\%), encontrándose además diferencias significativas del 0.05 ; el $20.3 \%$ lo consideraría un acto vergonzoso; $18.1 \%$ como una experiencia desagradable. Existe un $3.6 \%$ que no le atribuye ninguna importancia a éstos hechos, de ellos los niños en un $2.9 \%$ comparativamente a las niñas $(0.7 \%)$, existiendo diferencias significativas del 0.05 .

\section{Tabla $\mathrm{N}^{0} 6$ \\ Temor a ser abusado sexualmente}

\begin{tabular}{|c|c|c|c|c|c|c|c|c|}
\hline \multirow{3}{*}{ Item } & \multirow{3}{*}{ Contenido de los Items } & \multicolumn{6}{|c|}{ Respuestas Afirmativas } & \multirow{3}{*}{$\mathrm{X} 2$} \\
\hline & & \multicolumn{2}{|c|}{ Hombres } & \multicolumn{2}{|c|}{ Mujeres } & \multicolumn{2}{|c|}{ Total } & \\
\hline & & & $\%$ & f & $\%$ & $\mathbf{f}$ & $\%$ & \\
\hline 30 & $\begin{array}{l}\text { ¿Alguna vez crees que alguien } \\
\text { ha querido abusar sexualmente } \\
\text { de tu persona? }\end{array}$ & 34 & 8.7 & 43 & 11.0 & 77 & 19.7 & 0.85919 \\
\hline 23 & $\begin{array}{l}\text { ¿Sientes miedo si te enteras que } \\
\text { un niño ha sido abusado } \\
\text { sexualmente? }(*)\end{array}$ & 136 & 34.81 & 178 & 45.5 & 314 & 80.31 & 0.00741 \\
\hline 21 & $\begin{array}{l}\text { Si te ofrecen un regalo o dinero } \\
\text { por acompañar a una persona } \\
\text { extraña. ¿Tú lo harías? }\end{array}$ & 6 & 1.5 & 3 & 0.8 & 9 & 23 & 0.13086 \\
\hline 24 & $\begin{array}{l}\text { Si te ofrecen llevarte a pasear, } \\
\text { sin que lo cuentes a tus padres } \\
\text { o familia. ¿Tú lo harías? }\end{array}$ & 11 & 2.8 & 10 & 2.6 & 21 & 5.4 & 0.70430 \\
\hline
\end{tabular}




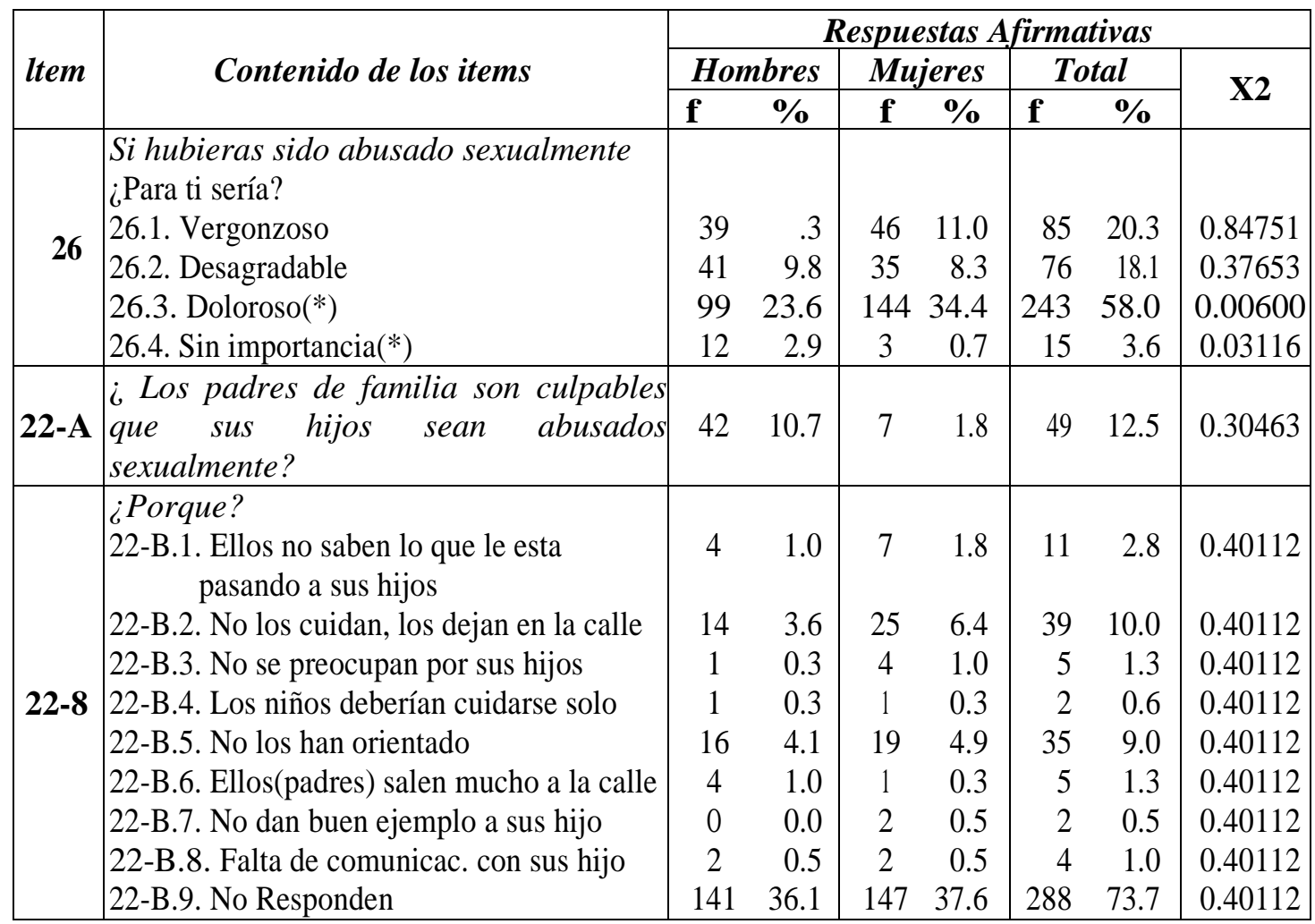

(*) Significativo al 0.05

Finalmente los niños encuestados consideran en un $75.2 \%$ (i.22-A) que los padres de familia no tienen la culpa de que sus hijos sean abusados sexualmente: en tanto que el $24.8 \%$ si asumen que los padres de familia son culpables en el caso que sus hijos sean abusados sexualmente.

CONDUCTA FRENTE AL AGRESOR SEXUAL, (ver Tabla No. 07) en ésta área observamos que la actitud frente al sujeto que agrede sexualmente a los niños es severa, el $35.1 \%$ (i.06) opina que debe ser detenido en la cárcel a cadena perpetua; el $26.0 \%$ que se le debe aplicar la pena de muerte; y el $07.9 \%$ la castración. Sin embargo el 28.9 $\%$ considera que se debe ayudar al agresor a que cambie o se regenere.

Ante la existencia de una posible agresión sexual el $47.5 \%$ (i. 32) de los encuestados manifiestan que gritaría pidiendo auxilio, de ellos son las niñas quienes mayormente recurrirían a esta acción en un $27.5 \%$ comparativamente a los niños (20.0 $\%$ ), existiendo diferencias significativas; el $30.9 \%$ solo se defendería; y el $11.9 \%$ opina que ofrecería resistencia negándose a ser abusado sexualmente. Existe una pequeña proporción de $4.5 \%$ que no sabría que hacer, de ellos el $3.1 \%$ de los niños comparativamente al $1.4 \%$ de las niñas, existiendo diferencias significativas del 0.05. 
El 61.6\% (i.09) asume que sabe como protegerse de una posible agresión sexual; en cuanto a la conducta que asumirían frente al agresor, el $43.2 \%$ gritaría pidiendo auxilio a cualquier persona; el $17.1 \%$ le pegaría y luego correría; el $14.3 \%$ evitaría ser agredido no haciendo caso a personas extrañas y no aceptando nada de nadie. Así mismo el $71.1 \%$ (i.28) de la muestra responde que sus profesores en el colegio los orientan a cómo protegerse o defenderse frente a un agresor o violador sexual.

Tabla $\mathbf{N}^{\circ} 7$

Conducta frente al agresor sexual

\begin{tabular}{|c|c|c|c|c|c|c|c|c|}
\hline \multirow{3}{*}{ Item } & \multirow{3}{*}{ Contenido de los items } & \multicolumn{6}{|c|}{ Respuestas Afirmativas } & \multirow{3}{*}{$\mathbf{X} 2$} \\
\hline & & \multicolumn{2}{|c|}{ Hombres } & \multicolumn{2}{|c|}{ Mujeres } & \multicolumn{2}{|c|}{ Total } & \\
\hline & & $\mathbf{f}$ & $\%$ & $\mathbf{f}$ & $\%$ & $\mathbf{f}$ & $\%$ & \\
\hline 6 & $\begin{array}{l}\text { Quién abusa sexualmente debería ser } \\
\text { sometido a: } \\
\text { 6.1. Pena de muerte } \\
\text { 6.2. Castración } \\
\text { 6.3. Detenerlo en la cárcel toda la vida } \\
\text { 6.4. Ayudarlo a que cambie } \\
\text { 6.5. Nada }\end{array}$ & \begin{tabular}{|l} 
\\
48 \\
16 \\
68 \\
48 \\
5
\end{tabular} & $\begin{array}{c}11.9 \\
4.0 \\
16.8 \\
11.9 \\
12\end{array}$ & $\begin{array}{c}57 \\
16 \\
74 \\
69 \\
4\end{array}$ & $\begin{array}{c}141 \\
4.0 \\
18.3 \\
17.0 \\
1.0\end{array}$ & $\begin{array}{c}105 \\
32 \\
142 \\
117 \\
9\end{array}$ & $\begin{array}{c}20.0 \\
8.0 \\
35.1 \\
28.9 \\
22\end{array}$ & $\begin{array}{l}079376 \\
0.70525 \\
0.74558 \\
0.13463 \\
0.36118\end{array}$ \\
\hline 32 & $\begin{array}{l}\text { ¿Qué harias si un extraño pretende } \\
\text { abusar de ti? } \\
\text { 32.1. Me niego } \\
\text { 32.2. Me defiendo } \\
\text { 32.3. No hago nada } \\
\text { 32.4. Pido auxilio gritando (") } \\
\text { 32.5. No opongo resistencia } \\
\text { 32.6. No sé }(*)\end{array}$ & \begin{tabular}{|c}
23 \\
61 \\
9 \\
84 \\
3 \\
13
\end{tabular} & $\begin{array}{c}5.5 \\
14.5 \\
2.1 \\
20.0 \\
0.7 \\
3.1\end{array}$ & $\begin{array}{c}27 \\
69 \\
4 \\
116 \\
6 \\
6\end{array}$ & $\begin{array}{c}6.4 \\
16.4 \\
1.0 \\
27.5 \\
1.4 \\
1.4\end{array}$ & $\begin{array}{c}50 \\
130 \\
13 \\
200 \\
9 \\
19\end{array}$ & $\begin{array}{c}11.9 \\
30.9 \\
3.1 \\
47.5 \\
2.1 \\
4.5\end{array}$ & $\begin{array}{l}0.90301 \\
0.97323 \\
0.09930 \\
0.05145 \\
0.41260 \\
0.05286\end{array}$ \\
\hline 9-A & $\begin{array}{l}\text { ¿Sabes como protegerte si alguien } \\
\text { quiere violarte? }\end{array}$ & 123 & 31.5 & 118 & 30.1 & 241 & 61.6 & 0.08399 \\
\hline
\end{tabular}




\begin{tabular}{|c|c|c|c|c|c|c|c|c|}
\hline \multirow{3}{*}{ Item } & \multirow{3}{*}{ Contenido de los Items } & \multicolumn{6}{|c|}{ Respuestas afirmativas } & \multirow{3}{*}{$\mathrm{X} 2$} \\
\hline & & \multicolumn{2}{|c|}{ hombres } & \multicolumn{2}{|c|}{ Mujeres } & \multicolumn{2}{|c|}{ Total } & \\
\hline & & f & $\%$ & f & $\%$ & f & $\%$ & \\
\hline \multirow{11}{*}{ 9-B } & ¿Cómo? & & & & & & & \\
\hline & $\begin{array}{l}\text { 9-B.1. Pedir auxilio, gritar, avisar a cualquier } \\
\text { persona ... }\end{array}$ & 67 & 17.1 & 102 & 26.1 & 169 & 43.2 & 0.11518 \\
\hline & 9-B.2. Le pegaría y correría & 31 & 7.9 & 36 & 9.2 & 67 & 17.1 & 0.11518 \\
\hline & 9-B.3. Me defiendo tirándole patadas, piedras... & 8 & 2.0 & 3 & 0.8 & 11 & 2.8 & 0.11518 \\
\hline & 9-B.4. Me escaparía & 13 & 3.3 & 15 & 3.9 & 28 & 7.2 & 0.11518 \\
\hline & 9-B.5. Avisaría a mis padres. & 14 & 3.6 & 10 & 2.5 & 24 & 6.1 & 0.11518 \\
\hline & 9-B.6. Avisaría a la policía & 11 & 2.8 & 14 & 3.6 & 25 & 6.4 & 0.11518 \\
\hline & $\begin{array}{l}\text { 9-B.7. No haciendo caso a extraños ni aceptar } \\
\text { nada de nadie }\end{array}$ & 34 & 8.7 & 22 & 5.6 & 56 & 14.3 & 0.11518 \\
\hline & 9-B.8. Hablar seriamente con el & 4 & 1.0 & 5 & 1.3 & 9 & 2.3 & 0.11518 \\
\hline & 9-B.9. Avisarle a mi profesor & 0 & 0.0 & 1 & 0.3 & 1 & 0.3 & 0.11518 \\
\hline & 9-B.10. Busco ayuda en una persona... & 1 & 0.3 & 0 & 0.0 & 1 & 0.3 & 0.11518 \\
\hline 28 & $\begin{array}{l}\text { ¿Tus profesores en el colegio, te dicen como } \\
\text { defenderte o protegerte y no ser abusado } \\
\text { sexualmente? }\end{array}$ & 128 & 32.7 & 150 & 38.4 & 278 & 71.1 & 0.89173 \\
\hline \multirow{6}{*}{5} & Aquel que viola a los niños es un persona & & & & & & & \\
\hline & 5.4. Loca & 44 & 10.9 & 59 & 14.4 & 103 & 25.3 & 0.33304 \\
\hline & 5.5. Enferma & 80 & 19.6 & 107 & 26.1 & 187 & 45.7 & 0.12698 \\
\hline & 5.6. Es delincuente & 49 & 12.0 & 51 & 12.4 & 100 & 24.4 & 0.60980 \\
\hline & 5.7. Es normal & 4 & 1.0 & 2 & 0.5 & 6 & 1.5 & 0.32577 \\
\hline & 5.8. Es pordiosera o mendigo & 7 & 1.7 & 6 & 1.5 & 13 & 3.2 & 0.60474 \\
\hline
\end{tabular}

\section{(*) Significativo al 0.05}

En cuanto a la condición o apariencia que presenta el violador sexual es percibida por los niños, como personas enfermas en un $45.7 \%$ (i.05): como locas en un 25.3\%; como delincuentes en un $24.4 \%$. 
CRITERIO VALORATIVO RESPECTO A SU CUERPO, (Tabla No.08) vemos que el $97.2 \%$ (i.25) de la muestra, rechaza tajantemente a cualquier persona que pretenda acariciarle a escondidas las partes intimas de su cuerpo y que están protegidas por su ropa interior. Luego el $80.8 \%$ (i.18) considera que su cuerpo es sólo suyo y por tanto nadie tiene el derecho a tocárselo si no lo desea.

Igualmente el $96.9 \%$ (i.19) no esta de acuerdo que los niños caminen con su cuerpo desnudos delante de personas adultas y desconocidas. El $78.1 \%$ (i.29) considera que le hace sentir mal y rechaza cualquier insinuación que sobre su cuerpo y su sexualidad pretendan abordarlo.

El 81.8\% (i.31 ) están de acuerdo en señalar que los niños tienen derecho a defenderse y negarse a aceptar aquellos tocamientos que resulten desagradables para ellos.

Tabla $\mathbf{N}^{\circ} 8$

Actitud valorativa respecto a su cuerpo

\begin{tabular}{|c|c|c|c|c|c|c|c|c|}
\hline \multirow{3}{*}{ Item } & \multirow{3}{*}{ Contenido de los Items } & \multicolumn{6}{|c|}{ Respuestas Afirmativas } & \multirow{3}{*}{$\mathrm{X} 2$} \\
\hline & & \multicolumn{2}{|c|}{ Hombres } & \multicolumn{2}{|c|}{ Mujeres } & \multicolumn{2}{|c|}{ Total } & \\
\hline & & $\mathbf{f}$ & $\%$ & $\mathbf{f}$ & $\%$ & f & $\%$ & \\
\hline 25 & $\begin{array}{l}\text { ¿Aceptas que te acaricien en } \\
\text { tus partes intimas? }\end{array}$ & & 1.5 & 5 & 1.3 & 11 & 2.8 & 0.75531 \\
\hline 18 & $\begin{array}{l}\text { ¿Sabes que nadie puede tocar } \\
\text { tu cuerpo, si no lo deseas? }\end{array}$ & 146 & 37.4 & 167 & 42.7 & 313 & 80.1 & 0.24227 \\
\hline 19 & $\begin{array}{l}\text { ¿Esta bien que los niños } \\
\text { caminen desnudos frente a } \\
\text { adultos y desconocidos? (*) }\end{array}$ & 7 & 1.8 & 5 & 1.3 & 12 & 3.1 & 0.05127 \\
\hline 31 & $\begin{array}{ll}\text { Los niños tienen derecho a } \\
\text { defenderse o negarse } & a \\
\text { tocamientos desagradables } & \end{array}$ & 145 & 37.1 & 175 & 44.7 & 320 & 81.8 & 0.44542 \\
\hline 29 & $\begin{array}{l}\text { Cuando estas a solas y alguien } \\
\text { te dice cosas sobre tu cuerpo y } \\
\text { tu sexualidad, ¿Esto te hace } \\
\text { sentir mal? }\end{array}$ & 141 & 36.1 & 165 & 42.2 & 306 & 78.3 & 0.49161 \\
\hline
\end{tabular}

(*) Significativo al 0.05 
AMBITO DE PROCEDENCIA DEL ABUSADOR SEXUAL, (ver Tabla No.09) la población encuestada cree en relación a las personas que más frecuentemente cometen actos de abuso sexual con los niños, son personas desconocidas en un 39.8\% (i.11); el padrastro en un $26.3 \%$ los amigos en un $10.1 \%$; el papá en un $8.1 \%$; otro pariente en un $7.0 \%$.

En lo referente a la percepción de los niños sobre la existencia de personas con intención de molestar sexualmente a los niños o niñas a la salida del colegio, el $61.9 \%$ (i.13) opina que no los hay; siendo un $38.1 \%$ quienes responden que sí existen éste tipo de personas.

\section{Tabla $\mathbf{N}^{\circ} 9$ \\ Ámbito de procedencia del abusador sexual}

\begin{tabular}{|c|c|c|c|c|c|c|c|c|}
\hline \multirow{3}{*}{ ltem } & \multirow{3}{*}{ Contenido de los Items } & \multicolumn{7}{|c|}{ Respuestas Aflrmativas } \\
\hline & & \multicolumn{2}{|c|}{ Hombres } & \multicolumn{2}{|c|}{ Mujeres } & \multicolumn{2}{|c|}{ Total } & \multirow{2}{*}{$\mathrm{X} 2$} \\
\hline & & $\mathrm{f}$ & $\%$ & f & $\%$ & f & $\%$ & \\
\hline \multirow{9}{*}{11} & $\begin{array}{l}\text { Quienes más frecuentemente } \\
\text { abusan de niños son: }\end{array}$ & & & & & & & \\
\hline & 11.1. El padre & 23 & 4.5 & 19 & 3.6 & 4.2 & 8.1 & 0.27390 \\
\hline & 11.2. El padrastro & 55 & 10.6 & 81 & 15.7 & 136 & 263 & 0.06560 \\
\hline & 11.3. El tío & 7 & 1.4 & 10 & 1.9 & 17 & 3.3 & 0.63451 \\
\hline & 11.4. Otro pariente & 17 & 3.3 & 19 & 3.7 & 36 & 7.0 & 0.95782 \\
\hline & 11.5. Un amigo & 29 & 5.6 & 23 & 4.5 & 52 & 10.1 & 0.16404 \\
\hline & 11.6. El hermano & 6 & 11 & 3 & 0.5 & 9 & 1.7 & 0.31279 \\
\hline & 11.7. Un vecino & 8 & 1.6 & 11 & 2.1 & 19 & 3.7 & 0.67395 \\
\hline & 11.8. Un desconocido & 89 & 172 & 117 & 22.6 & 206 & 39.8 & 0.19767 \\
\hline 13 & $\begin{array}{l}\text { AI salir del colegio, ¿Encuentras } \\
\text { personas que molestan } \\
\text { sexualmente a los niños? }\end{array}$ & 63 & 16.1 & 86 & 22.0 & 149 & 38.1 & 0.35781 \\
\hline
\end{tabular}

\section{DISCUSION}

Los resultados encontrados nos indican que mayormente los niños (as) consideran que las fotografías de mujeres desnudas en los periódicos estimulan la conducta de abuso sexual en algunos sujetos. Este exhibicionismo de féminas desnudas lo vemos a diario sin ninguna restricción en la llamada "prensa amarilla", en el quiosco de la esquina. Sin que hasta la fecha se haya tomado una medida restrictiva y efectiva por parte de las autoridades locales con fines de prevención y a fin de evitar la incidencia de este tipo de delitos. 
Otros medios que podrían propiciar la estimulación de similares conductas en prejuicio de los menores, los tenemos en las películas de violencia sexual que se ven en el cine y la TV., igualmente sin ninguna restricción e incluso en horarios impropios para menores.

Así mismo encontramos que los medios de comunicación tales como la TV. en primer orden y los periódicos en segundo orden, son los canales por los cuales niños y niñas se informan de las víctimas abusadas sexual mente. Un papel efectivo que cumplen los medios de comunicación, entre ellos la TV. y los periódicos, es que permite a las personas y en particular a los niños informarse sobre las noticias que están relacionadas con hechos ocurridos de abuso o violación sexual, información que probablemente impacta al menor y lo coloca en una situación defensiva.

Solo en niveles bajos parece ser que la muestra discrimina un acto de abuso sexual realizado por un sujeto a un niño(a), diferenciando las siguientes conductas: cuando una persona toca sus órganos genitales o partes sexuales, si alguien le manosea su cuerpo, o cuando una persona extraña le pide al niño que se quite su ropa interior, o también cuando otra persona le pide que haga tocamiento de sus partes sexuales, así mismo cuando alguna persona se desnuda en presencia del niño. Parece ser que la mayoría de niños (as) no tiene un entendimiento claro del momento en que es sometido al abuso sexual, lo que pondría en mayor riesgo al niño(a) de ser víctima de éste tipo de agresión.

Los niños(as) abusados sexualmente en opinión promedio de la muestra se debe a que fueron engañados habiendo recibido probablemente a cambio dulces o caramelos. Debemos reconocer que los niños son manejables fácilmente y es posible que todavía no estén en condiciones de discernir la intención de otras personas respecto a éstos hechos, además su nivel de pensamiento estaría dentro de las operaciones concretas. Por cierto también es importante la orientación que puedan recibir de parte de sus padres, lo que al parecer, solo se da en mínimos casos, siendo que la mayoría de niños no son aconsejados por sus padres tomándose vulnerables.

Las edades consideradas de alto riesgo por la muestra, en opiniones por encima del promedio, estarían comprendidas entre los 03 a 05 años de edad, siendo significativamente alta la respuesta de los niños. Es evidente que ésta es una de las edades más indefensas del ser humano, y que por cierto requiere de mucha atención y protección por parte de los padres, familiares o tutores, situación que en nuestro medio muchas veces se deja de lado, En cambio las niñas consideran que las edades de mayor riesgo pueden ser entre los 08 y 10 años de edad, siendo significativamente alta su opinión. Estos resultados estarían indicando que las niñas tienen mayor temor a ser abusadas sexualmente, lo que coincide con algunos estudios que señalan estas edades como de mayor incidencia de abuso sexual en niñas. 
La impresión que tiene la muestra en niveles superiores al promedio y con relación al niño abusado sexualmente, es de tener la apariencia de estar psicológicamente traumados y en opiniones más bajas los consideran enfermos y sexual mente anormales. Así mismo en grupos superiores al promedio los percibidos como sujetos tristes, siendo significativamente alta la apreciación de las niñas; luego son vistos como afeminados o "maricones", en opiniones significativas por los niños. Estos pareceres reflejan los rasgos personales característicos en las niñas y niños, evidenciándose en éstos últimos los prejuicios machistas provenientes de su entorno familiar o ambiental. En tanto que las niñas expresan mas bien sentimientos de ternura. La respuesta a la pregunta ¿Qué hacer con un niño abusado sexualmente? se da por debajo del promedio, y las alternativas se orientan a brindarles protección, y seguidamente llevarlos a la policia. Los niños son quienes responden significativamente que debe formularse la denuncia policial respectiva, probablemente a fin de que las autoridades investiguen y se castigue al autor de ese delito. Así mismo consideran que primeramente el niño(a) debe recibir atención psicológica y luego atención médica. Nosotros estamos de acuerdo que en algunos casos es posible que sea prioritaria la atención médica en un niño abusado sexualmente, pero el criterio inicial de atención psicológica no deja de ser impollante si asumimos que la víctima de abuso sexual muchas veces no es lesionada físicamente y en consecuencia es mayor el daño psicológico, pudiendo afectarse en su estado emocional, perdida de su autoestima, ideas angustiantes, reacciones neuróticas o psicóticas, incluso la víctima podría llegar hasta el suicidio.

Encontramos que existe significativamente buena relación de comunicación de las niñas con sus madres, ante una posible agresión sexual, ya que eligen contarles inmediatamente sobre éstos hechos a la mamá, y no al papá; tal vez porque no tienen confianza con el padre para hablar sobre sexualidad, o por la reacción de agresividad y castigo fisico que usualmente aplican como solución los padres de bajo estrato social en nuestro medio, económico, o también porque simplemente se tiene padrastros y prefieren omitir hablar de estos asuntos.

En niveles por encima del promedio la muestra de estudio considera que existe mayor peligro y riesgo de abuso sexual en las niñas, siendo significativamente altas las respuestas de las niñas. En segundo orden estarían las mujeres jóvenes y en tercer orden los niños. Es posible que al imaginarse de esta agresión las niñas sientan mayor angustia y lo asocien a los hechos traumáticos que suelen ocurrir, como raptos, violaciones, descuartizamientos de mujeres, etc. Los reportes estadísticos sobre abuso sexual igualmente revelan que las niñas registran un alto índice de violación sexual.

Se encuentra un regular nivel de información sobre casos de niños (as) víctimas de abuso sexual. Es probable que toda esta información sea recogida por la T.V. o los 
periódicos, otro medio es por lo que escuchan en el barrio a través de vecinos o amigos; en su casa de las conversaciones o comentarios de sus padres o familiares, incluso en el colegio de lo que dicen sus profesores o compañeros.

Los temores a ser abusados sexualmente en la muestra son altos, siendo las niñas quienes presentan significativamente mayores preocupaciones y temores; sin embargo también es alta la frecuencia de respuestas que niegan haber experimentado algún ataque o agresión sexual. Por ello, la mayoría de niños(as) rechazaria algún regalo de persona extrana y mucho menos sí son invitado a pasear sin tener consentimiento de sus padres. Una agresión sexual es considerada por las niñas, significativamente como algo doloroso. Estas respuestas evidencian la búsqueda de seguridad y protección, considerando peligrosa esta situación.

La conducta frente al agresor sexual manifestada por los niños aunque en niveles bajos es principalmente de tendencia punitiva, es decir emplearían castigos duros para el victimario como encarcelamiento a cadena perpetua, pena de muerte e incluso la castración. Como actitud defensiva, las niñas responden significativamente que gritarían pidiendo auxilio, en tanto que los niños le pegarían y luego correrían; también algunos niños contestan significativamente que no sabrían que hacer ante esa eventualidad. Mayormente los niños confiesan que son orientados por sus profesores para protegerse del agresor sexual quien además es percibido como una persona enferma, loca o delincuente. Sin embargo el abusador sexual no siempre presenta ésta apariencia.

En lo concerniente a su cuerpo, los niños(as) tienen una alta valoración, consideran que su cuerpo es solo suyo y por tanto nadie tiene derecho a tocárselo, igualmente rechazarían cualquier insinuación que sobre su cuerpo y su sexualidad pretendan hacer otras personas, además no aceptan que un niño camine desnudo delante de otras personas desconocidas. Se aprecia en la muestra un real sentido de aprecio por su cuerpo y posiblemente intuyan que la desnudez los coloca en el riesgo de ser víctimas de agresiones sexuales.

No existe una clara identificación del ámbito de procedencia del abusador sexual, un tercio señala que son personas desconocidas, menos de un tercio el padrastro, los amigos, el papá, los parientes. Estas respuestas aunque en bajos niveles son coincidentes con los resultados de diversos estudios que señalan como autores de abuso sexual a los familiares de la víctima. 


\section{CONCLUSIONES}

1. Los medios de comunicación: periódicos, cine y T.V. que exhiben fotografías de mujeres desnudas, películas de violencia sexual y desnudos, estimulan la conducta de abuso sexual en algunos sujetos.

2. Los medios de comunicación: periódicos y T.V. mantienen informados a los niños(as) sobre casos de abuso sexual y violación sexual.

3. Los niños varones responden significativamente que las edades de mayor riesgo en los infantes de ser abusadas sexualmente es la de 03 a 05 años de edad; en tanto que las niñas responden significativamente que las edades de mayor riesgo de ser abusados sexual mente son los niños(as) de 08 a 10 años de edad.

4. Se encuentra en niveles significativos que existen adecuadas relaciones de comunicación de las niñas con sus madres, ante una posible agresión sexual.

5. En niveles significativos las niñas reconocen que están en mayor peligro de ser abusadas sexual mente, siendo también significativos sus temores y preocupaciones al respecto.

6. Una posible experiencia de abuso sexual es percibida significativamente por las niñas como algo doloroso.

7. Los niños(as) mayormente presentan una alta valoración con relación a su cuerpo y por tanto no aceptan ningún requerimiento sexual que con su cuerpo pretenda hacer alguna persona.

\section{BIBLIOGRAFIA}

ARRUABARRENA, I Y DE PAUL, J. (1994) Maltrato a los niños en la familia. Ediciones Pirámide, Madrid-España.

BESTEN, Beate (1995) Abusos sexuales en los niños. Editorial Herder, Barcelona España.

DUGHI, MACHER, MENDOZA y NUNEEZ (1995) Salud Mental, Infancia y Familia, Unicef. Editorial IEP ediciones, Lima-Perú.

GALLARDO, Jose A. (1988) Malos tratos a los niños, Ediciones Narcea S.A., MadridEspaña. 
HOOPER. Carol (1992)

Madres sobrevivientes al abuso sexual de sus niños, Ediciones Nueva Visión, Buenos Aires.

ELIACHERR, Caroline (1997) Del niño rey al niño víctima, Ediciones Nueva Visión, Buenos Aires.

FELIX C., Pablo (1997) La violencia y el abuso sexual contra menores, Editado por Solidaridad Desarrollo, Lima-Perú.

KATCHADOURIAN, Herant (1993) La sexualidad humana, un estudio comparativo de su evolución, Editorial Fondo de Cultura Económica, México.

KAZDIN, A. Y BUELA CASAL, G. (1998) Conducta Antisocial, Ediciones Piramide, Madrid-España.

KEMPE, R. Y KEMPE, H. (1996) Niños Maltratados, Ediciones Morara, Madrid, España.

LEON y MONTERO (1997) Diseño de investigaciones, Editorial Mc Graw-Hill, España.

LOPLL CANO, .José, (1997) Método e hipótesis científicos, Editorial Trillas, México.

ARTINEZ y OCHOTORENA, J. (1993) Maltrato y abandono en la infancia, Editorial Martínez Roca, Barcelona-España.

MUSSEN, CONGER y KAGAN (1994) Desarrollo de la Personalidad del Niño, Editorial Trillas, México.

PAPALIA, Diane y WENDKOS, Sally (1992) Psicología del Desarrollo, De la Infancia a la Adolescencia, Editorial McGraw-Hill Interamericana S.A., México.

PONCE GARCIA, Silvia (1995) Estudio Epidemiológico sobre Maltrato Infantil en Población Escolarizada de Lima Metropolitana y Callao CEDRO, Lima-Perú 